\title{
ANALYSIS AND MITIGATION OF UNBALANCE DUE TO LOAD IN DISTRIBUTION SYSTEM BY USING ACTIVE POWER FILTER
}

\author{
A.N.V.V. Raja Sekhar ${ }^{1}$, D. Jagadeesh Babu ${ }^{2}$, S.Viswanadh $^{3}$, K.Harika ${ }^{4}$ \\ ${ }^{1}$ Assistant Professor, ${ }^{2,3,4}$ IV B.Tech, EEE, St.Ann's College of Engg. \&Tech., Andhra Pradesh, India, \\ blosoms2007@gmail.co,mnani.jagadeesh909@gmail.com,viswab69@gmail.com,harika.koppolu@gmail.com
}

\begin{abstract}
Distribution network losses can vary significantly depending on the load unbalance. Here, an analysis of distribution system losses is presented that considers load unbalance and the effect of explicitly represented neutral wire. A general power flow algorithm for three-phase four-wire radial distribution networks, based on the current summation backward-forward technique is applied. Loss analysis results obtained from three-phase four-wire medium and low voltage test feeders with unbalanced load scenarios are presented and discussed an active power filter is designed, simulated, implemented, and tested. It can work in different modes: active power filtering, power factor correction, and load unbalance compensation. It is based on a current controlled voltage-source inverter with fixed carrier PWM. The control algorithm generates the source reference currents based on the controlled DC link voltage. The dimensioning criteria of the inductive and capacitive power components are discussed. The implementation is validated with simulated and experimental results obtained in a $5 \mathrm{kVA}$ prototype.
\end{abstract}

Keywords: distribution networks, losses, load unbalance, power flow

$* * *$

\section{INTRODUCTION}

Since system losses represent a considerable cost for utilities, its evaluation and reduction have been recognized as of interest by researchers. There are many distribution network devices responsible for energy loss, the most important being the primary and secondary lines, due mainly to overloaded low voltage (LV) feeders and unbalanced loads. Unbalance is a common occurrence in three-phase distribution systems. However, it can be harmful to the operation of the network, its reliability and safety. Furthermore, measurements show that real power losses increase due to unbalanced loads. Thus, a distribution system unbalance phenomenon has been the focus of research in recent decades [1]-[3]. This problem in distribution networks exists due to the fact that loads are switched on and off by end users [1]. Therefore, considering the importance of loss analysis, the objectives of this work are to evaluate losses due to load unbalance and highlight potential mistakes in loss analysis. It is assumed here that a load unbalance affects only the fundamental component of the neutral current since the harmonic power losses are, in general, small compared to the fundamental active power losses and could be considered as almost negligible.

Different types of compensators have been proposed to Increase the electric system quality, [4], [5], [6]. One of those compensators is the active power filter. Usually, the voltagesource is preferred to implement the parallel active power filter since it has some advantages, [4]. In this paper it is used the parallel topology, schematically shown in Fig. 1.

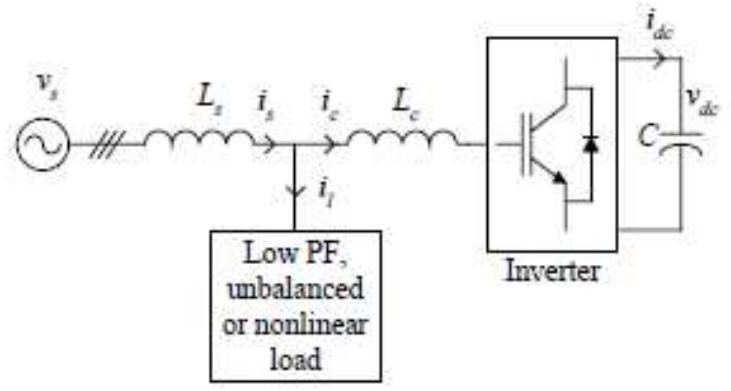

Fig. 1: Diagram of a voltage source active power filter.

The filter generates currents in the connection point in order to balance loads. So, the AC distribution system only carries the active fundamental component of the load current. A 5 $\mathrm{kVA}$ prototype of an active filter is designed, and tested in dynamic and stationary operation with different load types.

\section{LOSS EVALUATION}

In general, after solving the respective three-phase (fourwire or three-wire) power flow of a given distribution network, line section loss calculation can be performed utilizing one of the following procedures:

- Using the original resistances of the wires in the $I^{2} R$ formula. The sum of them gives the total losses. Here, phase Losses, neutral wire losses and total losses are correct.

- Using the difference between input and output power $\left(S_{\text {in }}\right.$ - $\left.S_{\text {out }}\right)$ in each phase. The sum of the phase losses $(a, b$ and 
c) gives the total losses, and it is not possible to compute the neutral losses. In this procedure the value of total losses is correct, but the losses in each phase are incorrect [8].

When four-wire line sections are represented by a reduced $3 \times 3$ matrix (performing Kron's reduction) in order to use a threephase power flow algorithm (such as [9]), phase voltages and currents will be obtained with acceptable accuracy. Since the neutral wire is explicitly represented in the utilized power flow technique [7], neutral currents are calculated directly. Thus, with all current values, power losses can be computed by using the original phase and neutral wire resistances in the $I^{2} R$ formula. System losses are calculated under various scenarios, from balanced loads (considered here, as the first unbalance scenario) to the highest load unbalance allowed by the analyzed system. In that way, the impact of load unbalance on system losses can be clearly visualized.

\section{TEST NETWORKS}

The proposed methodology for evaluation of power losses due to load unbalance is applied on MV and LV distribution networks. In this paper the LV 29 bus and MV IEEE 34 bus networks are used. The original. IEEE-34 test feeder is simplified by replacing the autotransformer $(24.9 \mathrm{kV} / 4.16$ $\mathrm{kV}$ ) with a line and the network is modeled at the single voltage level.

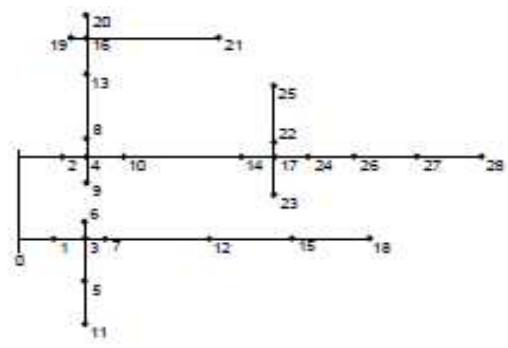

Fig.2: LV-29 distribution network

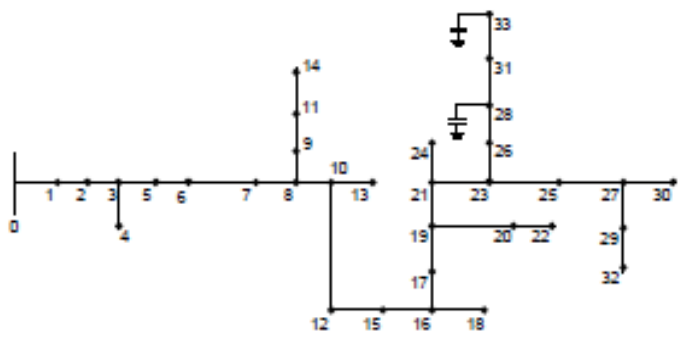

Fig.3: IEEE-34 test feeder

Impedances for the four-wire model are calculated considering a ground resistivity of $100 \Omega-\mathrm{m}$ and using the formulation in [7].

\subsection{Active Filter Operating Modes}

Very different control algorithms can be applied to the active filter, [10], [11], [12], [13]. The developed control system is based on a direct current control strategy that generates the reference waveform for the source current. It requires a low processing time and allows the calculation of the current reference. The current-controlled pulse width modulation with a $5 \mathrm{kHz}$ fixed carrier ensures enough bandwidth to implement the active filtering.

The control algorithm needs the measurement of several variables like the three phase AC source voltages and the DC link voltage. In order to impose sinusoidal currents in the source it is needed to low pass filter the AC voltage, so obtaining the fundamental component. The active power balance in the DC link determines the reference current of the AC source and the use of a PI controller allows a smooth control of the filter current and improves the system dynamic response.

\subsection{Unbalance Compensation}

As referred, in this paper it is implemented the first operating mode: power factor correction, harmonic elimination, and load unbalance compensation. So, the source power factor will be approximately one, and there in no need to control the voltage at the connection point. In this case, the schematic in Fig.3 represents the essential block diagram of the current reference. The error in the DC voltage is transformed in active power to be controlled in the AC source.

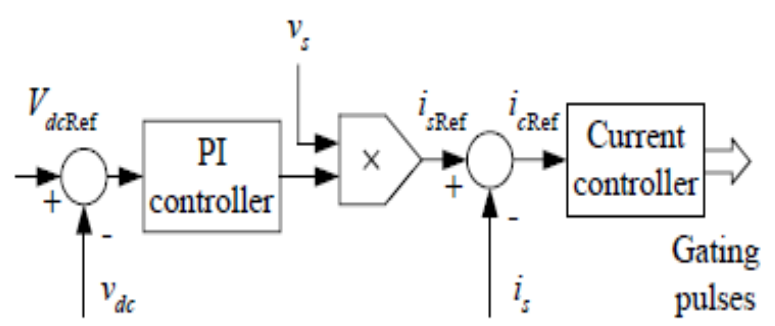

Fig. 4: Block diagram for the calculation of the reference current.

\subsection{Reference Current Determination}

The source voltage amplitude, $\mathrm{V}_{\mathrm{sp}}$ is calculated from the source phase voltages $\mathrm{v}_{\mathrm{sa}}, \mathrm{v}_{\mathrm{sb}}, \mathrm{v}_{\mathrm{sc}}$ as expressed in equation (1)

$$
V_{s p}=\sqrt{\frac{g}{s}\left(v_{s a}^{2}+v_{s b}^{2}+v_{s a}^{2}\right)}
$$

The direct unit current vectors are obtained from the source phase voltages and the rms amplitude of the source voltage, $\mathrm{V}_{\mathrm{sp}}$. 


$$
\begin{gathered}
u_{s a}=v_{s a} / v_{s p} \\
u_{s b}={ }^{v_{s b}} / v_{s p} \\
u_{s c}=v_{s c} / v_{s p}
\end{gathered}
$$

The amplitude of the active component of the reference currents of the AC source $i_{s a d}^{*} i_{s b a}^{*} i_{s o d}^{*}$ is calculated through a PI controller with anti-windup as shown in Fig. 4. The proportional and integral gains determine the controller behavior in dynamic and static operation, [11], [13], [14], [15]. As stated before the correct active component $I_{s p}^{*}$ of the AC source current is determined from the power balance in the DC link. The current reference is then scaled with the unit current vectors in phase with the source voltage.

$$
\begin{array}{r}
i_{s a}^{*}=I_{s p}^{e} \cdot u_{s a} \\
i_{s b}^{*}=I_{s p}^{e} \cdot u_{s b} \\
i_{s c}^{*}=I_{s p}^{*} \cdot u_{s o}
\end{array}
$$

In the modulation stage the total reference currents are subtracted from the source current, obtaining a current error adapted according to the amplitude of the triangular carrier. The purpose of introducing the triangular waveform is to stabilize the converter switching frequency by forcing it to be constant and equal to the frequency of the triangular reference signal. Since the current error signal is always kept within the negative and positive peaks of the triangular waveform, the system has an inherent over current protection. The PWM output is completed with the introduction of an appropriate dead time to the control signals of the inverter transistors.

\section{SIMULATION AND EXPERIMENTAL RESULTS}

In this work, power flow algorithm [7] is applied on the MV and LV distribution networks presented previously. The presentation is focused on the discrepancy of loss calculation. The load was modeled as constant power.

The following types of unbalance are considered: constant demand: Firstly the overall network load is balanced for the three phases. Subsequently, a percentage of the b-phase load is increased, while the same value is decreased in phase c. In this way, the total network load remains constant under each unbalance scenario.

Variable demand: Firstly the overall network load is balanced for the three phases. Afterward, a percentage of the load of phase b is decreased, while the decrease is twice this value in phase $\mathrm{c}$. This kind of unbalance reduces the total network load under each unbalanced scenario.

\subsection{Analysis of LV Distribution Network}

Figures 5 to 6 present real power losses for the LV-29 distribution network. Figure 3 shows results of the loss analysis for the LV-29 distribution network when the constant demand was applied. It is noticed that despite demand being maintained, total losses calculated by the explicit four-wire approach increased by $4.1 \%$ for a $15 \%$ unbalance as compared to a fully balanced system (EQ). This is mainly because the neutral wire is being considered.

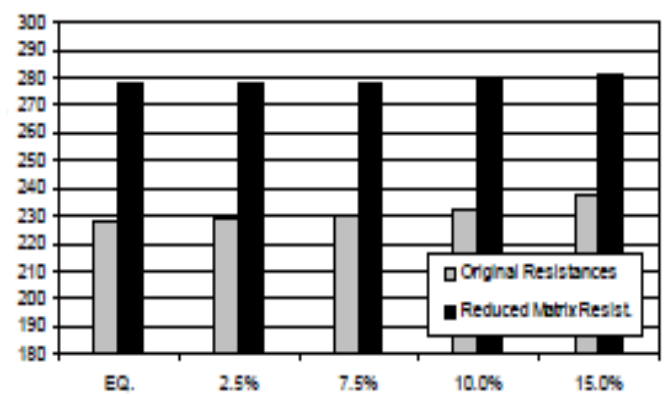

Fig 5: Real Power Losses for the LV-29 distribution network with constant demand.

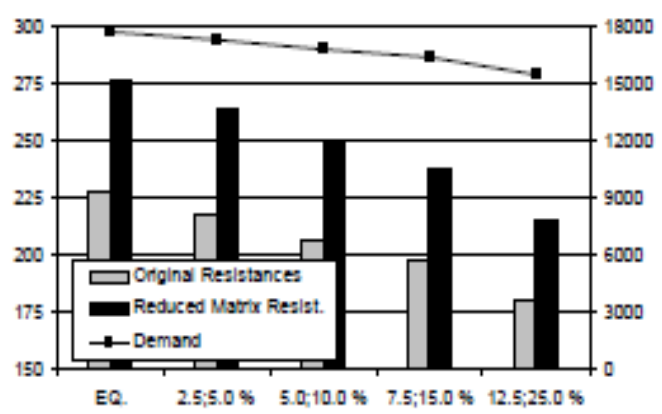

Fig 6: Real Power Losses for the LV-29 distribution network with variable demand.

Results of the loss analysis obtained by applying variable demand for the same distribution network are shown in Figure 6. Using the reduced matrix resistances leads again to larger losses than using original resistances. Due to the decrease in demand under each unbalance scenario, the amount of losses also decreased. Losses computed with original resistances diminished $21 \%$ at the last unbalance scenario, which in terms of demand $(17.7 \mathrm{~kW})$ means from 1.29 (balanced loads) to $1.13 \%$.

\subsection{Analysis of MV Distribution Network}

Figures 7 to 8 present real power losses for the IEEE-34 
distribution network. Results of loss analysis for the IEEE-34 distribution network applying the constant demand are shown in Figure 6. Total losses calculated with original phase and neutral wires resistances increased $4.9 \%$ compared to the balanced load scenario. Using reduced matrix resistances into the $I^{2} \mathrm{R}$ formula produces much larger results than the correct procedure.

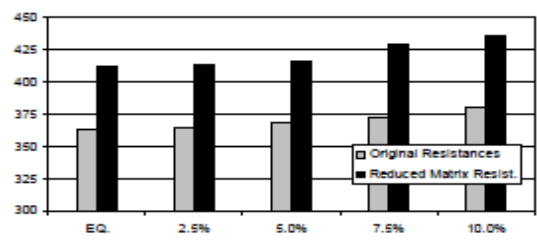

Fig 7: Real Power Losses for the IEEE-34 distribution Network with constant demand

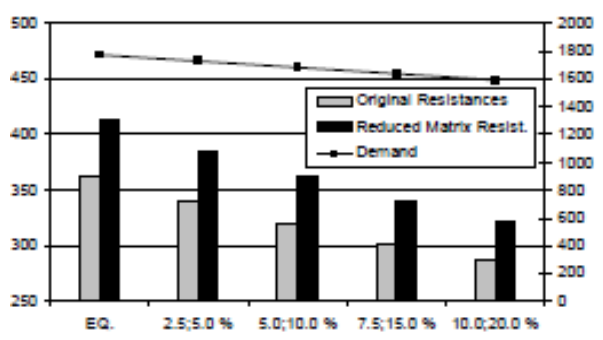

Fig 8: Real Power Losses for the IEEE-34 distribution Network with variable demand.

Figure 9 shows the results of loss analysis obtained by applying variable demand for the same network. Using reduced matrix resistances leads again to larger losses (13.3\% greater in average) than using original resistances. Losses computed with original resistances diminished $12.2 \%$ at the last unbalance scenario compared to the EQ. scenario. This represented, in terms of demand, a reduction from $20.5 \%$ to $18 \%$.

It should be noted that the percentage losses in the IEEE-34 distribution network are significantly greater than in the LV-29 network. The main reason for this situation is that load concentration in the IEEE-34 is far away from the root node. Moreover, the exclusion of the autotransformer and voltage regulators from the original IEEE-34 network allowed larger voltage drops and losses as well. The SABER simulation software package was used to design, simulate, and test the filter control algorithm. The static operation tests were made putting the active filter in operation when the load was already connected to the AC source voltage. The simulation of the filter operation in load unbalance compensation is shown in Fig.8.The load is connected between two phases; the third phase is an open circuit. Due to several factors the unbalance compensation is not perfect. It should be referred the DC voltage fluctuation caused by the unbalanced filter currents (if this condition would be the most important in the filter operation the DC capacitor value could be increased), and the effects of the asymmetries in the $\mathrm{AC}$ inductances.

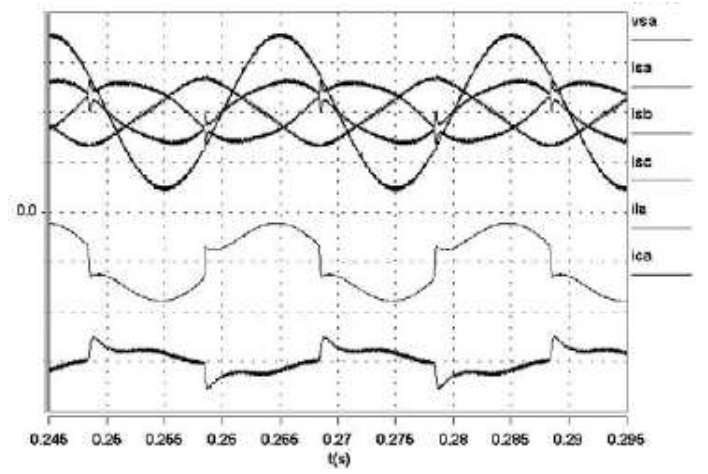

Fig 9: Load unbalances compensation

\subsection{Experimental Results}

An experimental three phase active filter prototype has been designed for a nominal power of $5 \mathrm{kVA}$. It is based on a voltage source inverter with MOSFET transistors and a switching frequency of $5 \mathrm{kHz}$. The experimental tests were conducted in a laboratory with an important distortion in the mains voltage, due to the proximity of a large number of nonlinear loads. However, the mains current waveform after compensation is almost a sine wave due to the extraction of the fundamental component of the mains voltage through low pass filters. This filter action allows the imposition of sine wave references for the source current; it could be possible to impose non sine wave references "in phase" with the mains voltage.

\section{CONCLUSIONS}

In this paper we presented a loss analysis in distribution systems considering different load unbalance scenarios. A general power flow algorithm for three-phase four-wire radial distribution networks, this approach improves loss calculation due to the explicit representation of the neutral conductor, which should be considered since unbalance is a common every-day occurrence in three-phase distribution systems. High levels of load unbalance produced greater losses while the same demand is maintained at each unbalance scenario. This means that network reconfiguration considering load balancing is highly recommend in order to diminish overall system losses. The presented implementation has been validated for balancing the loads, single or grouped, which cause great perturbation and performance degradation in the power quality of an electrical distribution system.

\section{REFERENCES}

[1] A. P. Meliopoulos, J. Kennedy, C. A. Nucci, A. Borghetti and G. Contaxies, "Power distribution practices in 
USA and Europe: Impact on power quality", 8th International Conference on Harmonics and Quality of Power Proceeding, pp 24-29, October 1998.

[2] J. C. Balda, A. R. Oliva, D. W. McNabb and R. D.Richardson, "Measurements of neutral currents and voltages on a distribution feeder", IEEE Trans. Power Delivery, 12(4), pp 1799-1804, October 1997.

[3] T. H. Chen and W. C. Yang, "Analysis of multigrounded four-wire distribution systems considering the neutral grounding", IEEE Trans. Power Delivery, 16(4), pp 710-717, October 2001.

[4]. M. H. Bollen, "Understanding Power Quality Problems: Voltage Sags and Interruptions", Wiley-IEEE Press, 1999.

[5]. N. G. Hingorani, L. Gyugyi, "Understanding Facts: Concepts and Technology of Flexible AC Transmission Systems", Wiley-IEEE Press, 1999.

[6]. H. Fujita, H. Akagi "The Unified Power Flow Conditioner: The Integration of Series- and Shunt-Active Filters", IEEE Transactions on Power Electronics, Vol.13, №2, pp.315-322, 1998.

[7]. R. M. Ciric, A. Padilha-Feltrin and L. F. Ochoa, "Power Flow in Four-Wire Distribution Networks General Approach", IEEE Trans on Power Systems, 18(4), pp 12831290, November 2003

[8]. W. H. Kersting, "The computation of neutral and dirt currents and power losses", IEEE-PES Transmission and Distribution Conference and Exposition Proceedings, 3, pp 978983,September2003.

[9]. C. S. Cheng and D. Shirmohammadi, "A three-phase power flow method for real-time distribution system analysis", IEEE Trans on Power Systems, 10(2), pp 671-769, May 1995.

[10]. J. W. Dixon, G. Venegas, L. Morán, "A Series Active Power Filter based on a Sinusoidal Current Controlled Voltage-Source Inverter", IEEE Transactions on Industrial Electronics, Vol.44, Nº5, pp.612-620, 1997.

[11]. A. Chandra, B. Singh, B. N. Singh, K. Al-Haddad, "An Improved Control Algorithm of Shunt Active Filter for Voltage Regulation, Harmonic Elimination, Power Factor Correction and Balancing of Nonlinear Loads", IEEE Trans on Power Electronics, Vol.15, N³, pp.495-507, 2000.

[12].P. Verdelho, G. D. Marques, "An Active Power Filter and Unbalanced Current Compensator", IEEE Transactions on Industrial Electronics, Vol.44, No3, pp.321-328, 1997.

[13]. S. Buso, L. Malesani, P. Mattavelli, "Comparison of Current Control Techniques for Active Filter Applications", IEEE Transactions on Industrial Electronics, Vol.45, $\mathrm{N}^{\mathrm{o}}$ 5, pp.722-729, 1998.

[14].C. Schauder, H. Mehta, "Vector Analysis and Control of Advanced Static VAR Compensators", IEE Proceedings, Part C, Vol.140, Nº, pp.299-306, 1993.

[15]. A. P. Martins, A. S. Carvalho, A. S. Araújo, "Modeling and Simulation of a Voltage Source Three Phase Active Power Filter", Proceedings of the European Simulation Congress, EUROSIM ‘95, Vienna, pp.735- 740, 1995.

\section{BIOGRAPHIES}

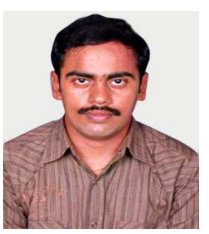

Mr. A.N.V.V. Raja Sekhar, M.Tech in Power Electronics working as an Assistant Professor in Electrical \& Electronics engineering department in St. Ann's College of Engineering \& Technology, Chirala affiliated to JNTU Kakinada. He is having $81 / 2$ years of teaching experience and good academic record. He presented 2 papers on international conferences and 6 papers on national conferences. He attended 6 national workshops related to electrical engineering.

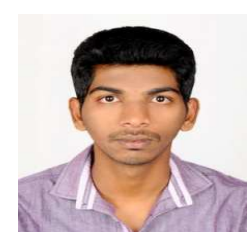

Mr. D. Jagadeesh babu pursuing B.Tech final year in the stream of Electrical\& Electronics engineering department in St. Ann's College of Engineering \& Technology, Chirala affiliated to JNTU Kakinada. He is having excellent academic record. He attended various workshops and presented different papers in various conferences and symposiums. He acted as a student coordinator for several events organized by the institution.

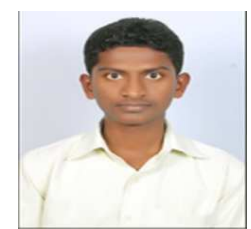

Mr. S. Viswanadh pursuing B.Tech final year in the stream of Electrical \& Electronics engineering department in St. Ann's College of Engineering \& Technology, Chirala affiliated to JNTU Kakinada. He is having excellent academic record. He presented various papers in conferences and symposiums and attended various workshops organized by various colleges.

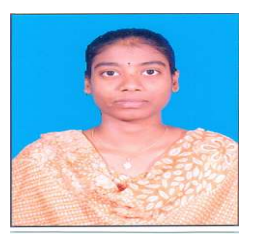

Ms. K. Harika studying final year B.Tech in the stream of Electrical \& Electronics engineering department in St. Ann's College of Engineering \& Technology, Chirala affiliated to JNTU Kakinada. She is having excellent academic record. She attended several workshops and conferences and presented various papers . 